\title{
Projected early spread of COVID-19 in Africa through 1 June 2020
}

Carl AB Pearson ${ }^{1,2}$, Cari Van Schalkwyk ${ }^{2}$, Anna M Foss ${ }^{1}$, Kathleen M 0’Reilly ${ }^{1}$, SACEMA Modelling and Analysis Response Team $^{2,3}$, CMMID COVID-19 working group ${ }^{1,4}$, Juliet RC Pulliam²

1. London School of Hygiene \& Tropical Medicine, London, United Kingdom

2. South African DSI-NRF Centre of Excellence in Epidemiological Modelling and Analysis (SACEMA), Stellenbosch University, Stellenbosch, Republic of South Africa

3. Members of the SACEMA Modelling and Analysis Response Team are listed at the end of this article

4. Members of the CMMID COVID-19 working group are listed at the end of this article

Correspondence: Carl AB Pearson (carl.pearson@lshtm.ac.uk)

Pearson Carl AB, Van Schalkwyk Cari, Foss Anna M, O'Reilly Kathleen M, SACEMA Modelling and Analysis Response Team , CMMID COVID-19 working group,

Pulliam Juliet RC. Projected early spread of COVID-19 in Africa through 1 June 2020. Euro Surveill. 2020;25(18): pii=2000543. https://doi.org/10.2807/1560-7917.

ES.2020.25.18.2000543

Article submitted on 07 Apr 2020 / accepted on 07 May 2020 / published on 07 May 2020

For 45 African countries/territories already reporting COVID-19 cases before 23 March 2020, we estimate the dates of reporting 1,000 and 10,000 cases. Assuming early epidemic trends without interventions, all 45 were likely to exceed 1,000 confirmed cases by the end of April 2020, with most exceeding 10,000 a few weeks later.

The World Health Organization (WHO) declared coronavirus disease (COVID-19) a public health emergency of international concern on 30 January 2020 [1] and then a pandemic on 11 March 2020 [2], highlighting its rapid global spread and risk of overwhelming healthcare services with patients requiring critical care. By 22 April 2020, WHO situation reports (SITREPS), indicated 56 African countries/territories reporting at least one laboratory-confirmed infection ('reported case') of COVID-19 [3]. We aim to estimate the timing of when countries/territories with early cases (reported before 10:00 Central European Summer Time (CEST) 23 March 2020, 45 of those 56) would report 1,000 and 10,000 cases [4].

\section{Assumptions, data sources and model used in the study}

Reported cases underestimate actual infections due to the mix of those resulting in mild disease and asymptomatic infections [5-7], the similarity of symptoms to other diseases common to lower-middle income countries [8], and the limitations of local surveillance systems [9]. However, assuming that the reporting fraction among actual cases and delay are constant, reported cases grow in proportion to the underlying epidemic, thus even with under-ascertainment of the number of actual cases, reported cases provide a useful predictor for stress on healthcare systems. We can use this surrogate for the real epidemic to forecast future trends, and understand what preparations need to be made now and the consequences of slow public health responses.

We employed a branching process model to project the number of future cases of COVID-19 in each country/territory. This model assumes each case produces a number of new cases (distributed $N \sim \operatorname{NegBinom}(R=2, k=0.58)$, using the reproductive number $R$ estimate from [10] and the dispersion $k$ estimate from [11]) occurring after some serial interval (distributed $T \sim \operatorname{LogNormal}(E[X]=4.7$, $\mathrm{SD}[X]=2.9$, in days, with the distribution characterised by the expected value (E) and standard deviation (SD)). We also considered $R=3$ as a sensitivity study given consensus that the reproductive number has been higher outside of Africa [12]. We start with cases timed according to the first 25 (or fewer) reported cases in the WHO SITREPs up to 23 March 2020 (SITREP 63) [4]. Using those epidemic parameters and initial cases and dates, we simulate the accumulation of reported cases. We assume there are always sufficient unreported infections to continue transmission, and that new cases represent a reporting sample from both identified and previously unidentified transmission chains. As long as a constant reporting fraction and delay persists during this period, and unreported spread is large relative to reported cases (or reporting does not represent effective control), this is a reasonable approximation.

For each set of country-specific initial conditions, we generate $n=10,000$ epidemics, discarding any that fade out, consistent with our assumption of unreported transmission chains. We identify the dates when each simulation run crosses 1,000 and 10,000 reported cases, and then evaluate the $50 \%$ and $95 \%$ quantiles of those dates to determine the forecast interval. The model was built in the $\mathrm{R}$ statistical programming 


\section{FIGURE 1}

Distribution of times when countries/territories already reporting COVID-19 cases by 23 March 2020 arrive at 1,000 and 10,000 reported cases, with inset map indicating median expected arrival dates by country/territory, Africa, 2020 ( $n=45$ countries/territories)

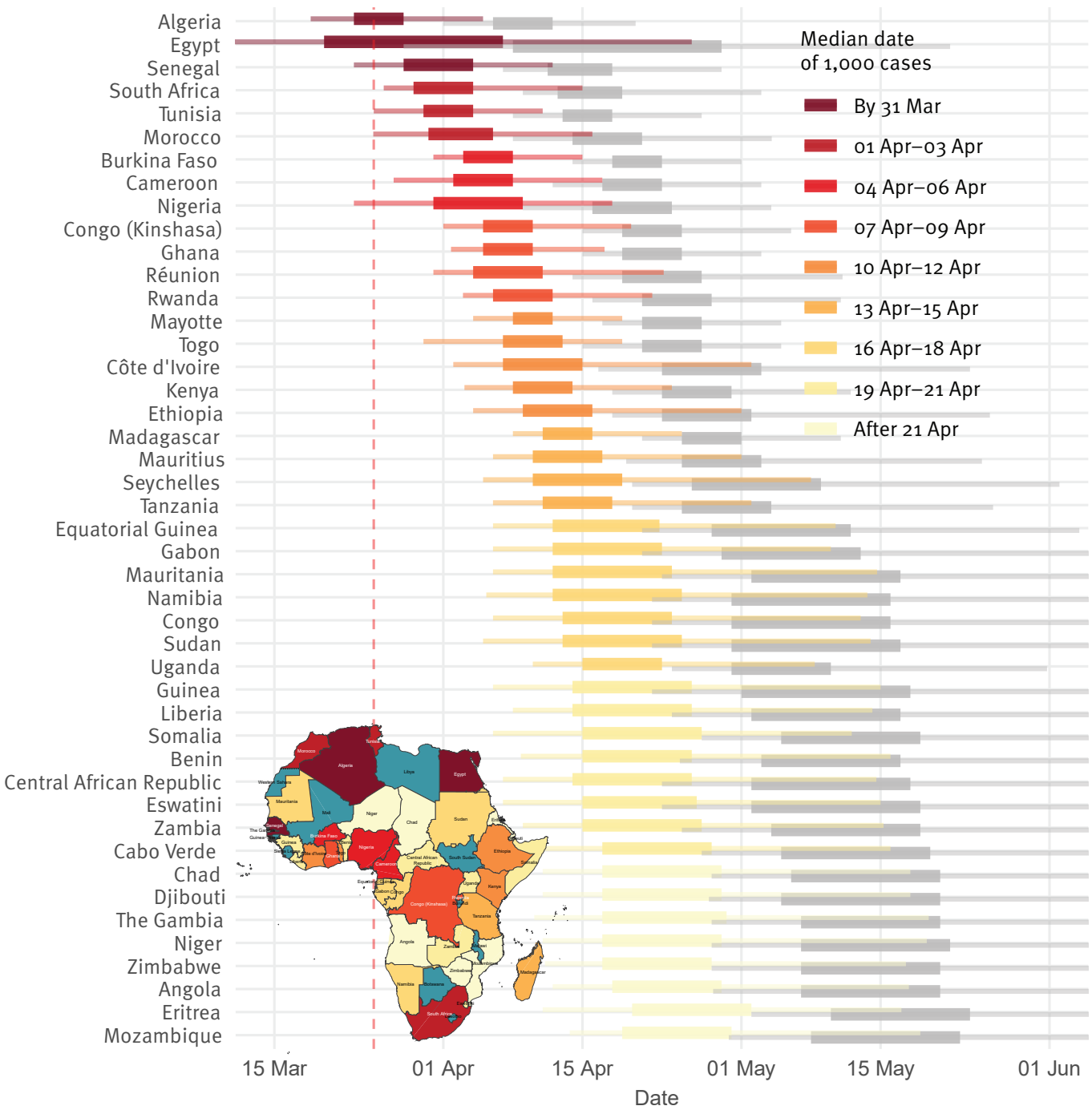

The boundaries and names shown on this map do not imply official endorsement or acceptance by the European Union.

For each country, the respective predicted dates of reaching 1,000 and 10,000 reported cases are each within coloured (dark red to yellow) and grey horizontal boxes, representing the $50 \%$ quantiles for these dates (i.e. $50 \%$ forecast intervals). The whiskers surrounding the boxes are $95 \%$ forecast intervals.

For the predicted periods of arrival at 1,000 reported cases, the horizontal boxes and whiskers are coloured according to a gradient from dark red to yellow. The dark red progresses to yellow as the forecast intervals of arrival to 1,000 reported cases are delayed in time.

The dashed vertical line indicates cut-off date for initial cases in the simulated epidemics.

The inset map indicates the median expected arrival dates at 1,000 reported cases by country/territory (dark red to yellow, corresponding to the forecast distributions); countries/territories not reporting cases by 23 March 2020 SITREP are in blue. 
TABLE

Projected timing of reporting of 1,000 and 10,000 COVID-19 cases for all African countries/territories reporting cases by 23 March 2020, assuming no change in reporting or introduction of control efforts, Africa, 2020 ( $n=45$ countries/territories)

\begin{tabular}{|c|c|c|c|}
\hline Country/territory & $\begin{array}{l}\text { Forecast intervals } 50 \%(95 \%) \\
\text { around date of } 1,000 \text { reported cases }\end{array}$ & $\begin{array}{l}\text { Forecast intervals } 50 \% \text { ( } 95 \%) \\
\text { around date of } 10,000 \text { reported cases }\end{array}$ & Date $\mathrm{SI}>30$ \\
\hline Algeria & 23 Mar-28 Mar (18 Mar-05 Apr) & 06 Apr-12 Apr (01 Apr-20 Apr) & $12 \mathrm{Mar}$ \\
\hline Angola & 18 Apr-29 Apr (12 Apr-17 May) & 07 May-21 May (28 Apr-12 Jun) & 24 Mar \\
\hline Benin & 15 Apr-26 Apr (o8 Apr-16 May) & 03 May-17 May (24 Apr-09 Jun) & 19 Mara $^{\mathrm{a}}$ \\
\hline Burkina Faso & 03 Apr-08 Apr (31 Mar-15 Apr) & 18 Apr-23 Apr (14 Apr-01 May) & 16 Mar \\
\hline Cabo Verde & 17 Apr-28 Apr (11 Apr-16 May) & 05 May-20 May (27 Apr-11 Jun) & 13 Mara $^{\mathrm{a}}$ \\
\hline Cameroon & $02 \mathrm{Apr}-08 \mathrm{Apr}$ (27 Mar-17 Apr) & 17 Apr-23 Apr (12 Apr-03 May) & 27 Mar \\
\hline Central African Republic & 14 Apr-26 Apr (o7 Apr-14 May) & 02 May-18 May (23 Apr-09 Jun) & $18 \mathrm{Mar}^{\mathrm{a}}$ \\
\hline Chad & 17 Apr-29 Apr (11 Apr-18 May) & o6 May-21 May (28 Apr-12 Jun) & 26 Mar \\
\hline Congo & 13 Apr-24 Apr (o6 Apr-13 May) & 30 Apr-16 May (22 Apr-06 Jun) & $19 \mathrm{Mar}^{\mathrm{a}}$ \\
\hline Côte d'Ivoire & 07 Apr-15 Apr (02 Apr-02 May) & 23 Apr-03 May (16 Apr-24 May) & $18 \mathrm{Mar}^{\mathrm{a}}$ \\
\hline Democratic Republic of the Congo & 05 Apr-10 Apr (01 Apr-19 Apr) & 19 Apr-25 Apr (15 Apr-06 May) & 19 Mar \\
\hline Djibouti & 17 Apr-29 Apr (11 Apr-18 May) & 05 May-21 May (27 Apr-12 Jun) & 19 Mar \\
\hline Egypt & 20 Mar-07 Apr (09 Mar-26 Apr) & 08 Apr-29 Apr (28 Mar-22 May) & 19 Mar \\
\hline Equatorial Guinea & 12 Apr-22 Apr (o6 Apr-10 May) & 28 Apr-12 May (21 Apr-04 Jun) & 15 Mara $^{\mathrm{a}}$ \\
\hline Eritrea & 20 Apr-02 May (11 Apr-17 May) & 10 May-24 May (02 May-11 Jun) & $17 \mathrm{Mar}^{\mathrm{a}}$ \\
\hline Eswatini & 15 Apr-26 Apr (07 Apr-15 May) & 02 May-19 May (23 Apr-10 Jun) & 17 Mar \\
\hline Ethiopia & 09 Apr-16 Apr (04 Apr-01 May) & 23 Apr-02 May (18 Apr-26 May) & 16 Mar $^{\mathrm{a}}$ \\
\hline Gabon & 12 Apr-23 Apr (o6 Apr-10 May) & 29 Apr-13 May (21 Apr-05 Jun) & 14 Mar \\
\hline Gambia & 17 Apr-29 Apr (10 Apr-19 May) & 07 May-21 May (28 Apr-12 Jun) & $18 \mathrm{Mar}$ \\
\hline Ghana & $05 \mathrm{Apr}-10 \mathrm{Apr}$ (01 Apr-17 Apr) & 19 Apr-25 Apr (15 Apr-03 May) & 16 Mar \\
\hline Guinea & 14 Apr-26 Apr (o6 Apr-15 May) & 01 May-18 May (22 Apr-09 Jun) & $26 \mathrm{Mar}^{\mathrm{a}}$ \\
\hline Kenya & $08 \mathrm{Apr}-14 \mathrm{Apr}$ (03 Apr-24 Apr) & 23 Apr-30 Apr (18 Apr-12 May) & 13 Mar \\
\hline Liberia & 14 Apr-26 Apr (o8 Apr-14 May) & 02 May-17 May (24 Apr-09 Jun) & $22 \mathrm{Mar}^{\mathrm{a}}$ \\
\hline Madagascar & $11 \mathrm{Apr}-16 \mathrm{Apr}$ (08 Apr-25 Apr) & 25 Apr-01 May (21 Apr-11 May) & 21 Mar \\
\hline Mauritania & 12 Apr-24 Apr (o6 Apr-14 May) & 02 May-17 May (23 Apr-07 Jun) & 19 Mar \\
\hline Mauritius & 10 Apr-17 Apr (06 Apr-01 May) & 25 Apr-03 May (19 Apr-25 May) & $20 \mathrm{Mar}$ \\
\hline Mayotte & 08 Apr-12 Apr (04 Apr-19 Apr) & 21 Apr-27 Apr (17 Apr-05 May) & $\mathrm{N} / \mathrm{A}$ \\
\hline Morocco & 30 Mar-06 Apr (24 Mar-16 Apr) & 14 Apr-21 Apr (08 Apr-04 May) & 13 Mar \\
\hline Mozambique & 19 Apr-30 Apr (13 Apr-19 May) & 08 May-23 May (29 Apr-14 Jun) & 24 Mar \\
\hline Namibia & 12 Apr-25 Apr (05 Apr-13 May) & 30 Apr-16 May (22 Apr-07 Jun) & 17 Mar \\
\hline Niger & 17 Apr-29 Apr (11 Apr-19 May) & 07 May-22 May (28 Apr-12 Jun) & 19 Mar \\
\hline Nigeria & 31 Mar-09 Apr (23 Mar-18 Apr) & 16 Apr-24 Apr (o9 Apr-04 May) & $18 \mathrm{Mar}$ \\
\hline Réunion & 04 Apr-11 Apr (31 Mar-23 Apr) & 19 Apr-27 Apr (14 Apr-11 May) & 14 Mar \\
\hline Rwanda & $06 \mathrm{Apr}-12 \mathrm{Apr}$ (02 Apr-22 Apr) & 21 Apr-28 Apr (16 Apr-11 May) & 14 Mar \\
\hline Senegal & $28 \mathrm{Mar}-04 \mathrm{Apr}$ (23 Mar-12 Apr) & $11 \mathrm{Apr}-18 \mathrm{Apr}$ (07 Apr-29 Apr) & $15 \mathrm{Mar}^{\mathrm{a}}$ \\
\hline Seychelles & 10 Apr-19 Apr (05 Apr-08 May) & 26 Apr-09 May (20 Apr-02 Jun) & 22 Mar \\
\hline Somalia & 15 Apr-27 Apr (o6 Apr-12 May) & 05 May-19 May (27 Apr-06 Jun) & 31 Mar $^{\mathrm{a}}$ \\
\hline South Africa & 29 Mar-04 Apr (26 Mar-15 Apr) & 12 Apr-19 Apr (o9 Apr-03 May) & 15 Mar \\
\hline Sudan & 13 Apr-25 Apr (05 Apr-14 May) & 30 Apr-17 May (22 Apr-08 Jun) & 14 Mar \\
\hline Togo & $07 \mathrm{Apr}-13 \mathrm{Apr}$ (30 Mar-19 Apr) & $21 \mathrm{Apr}-27 \mathrm{Apr}$ (15 Apr-05 May) & $20 \mathrm{Mar}^{\mathrm{a}}$ \\
\hline Tunisia & 30 Mar-04 Apr (25 Mar-11 Apr) & 13 Apr-18 Apr (o8 Apr-27 Apr) & 09 Mar \\
\hline Uganda & 15 Apr-23 Apr (10 Apr-08 May) & 30 Apr-10 May (24 Apr-31 May) & $18 \mathrm{Mar}$ \\
\hline Tanzania & 11 Apr-18 Apr (o6 Apr-02 May) & 25 Apr-04 May (20 Apr-26 May) & $18 \mathrm{Mar}$ \\
\hline Zambia & 15 Apr-27 Apr (og Apr-15 May) & 04 May-19 May (25 Apr-11 Jun) & $20 \mathrm{Mar}$ \\
\hline Zimbabwe & 17 Apr-28 Apr (11 Apr-17 May) & 07 May-21 May (28 Apr-11 Jun) & 23 Mar \\
\hline
\end{tabular}

COVID-19: coronavirus disease; N/A: data not available; SI: stringency index.

a Denotes countries where the date is estimated by manually coding from [17].

As a general assessment of the validity of assuming limited impact of control measures during the timeframe modelled, the last column denotes the date the SI [18] surpassed 30. The SI is an amalgamation of several intervention policies, which measures their formal declaration, and does not imply anything about their effectiveness. 


\section{FIGURE 2}

Forecast validation for countries having already reached 1,000 cases, $2020(n=39$ countries)

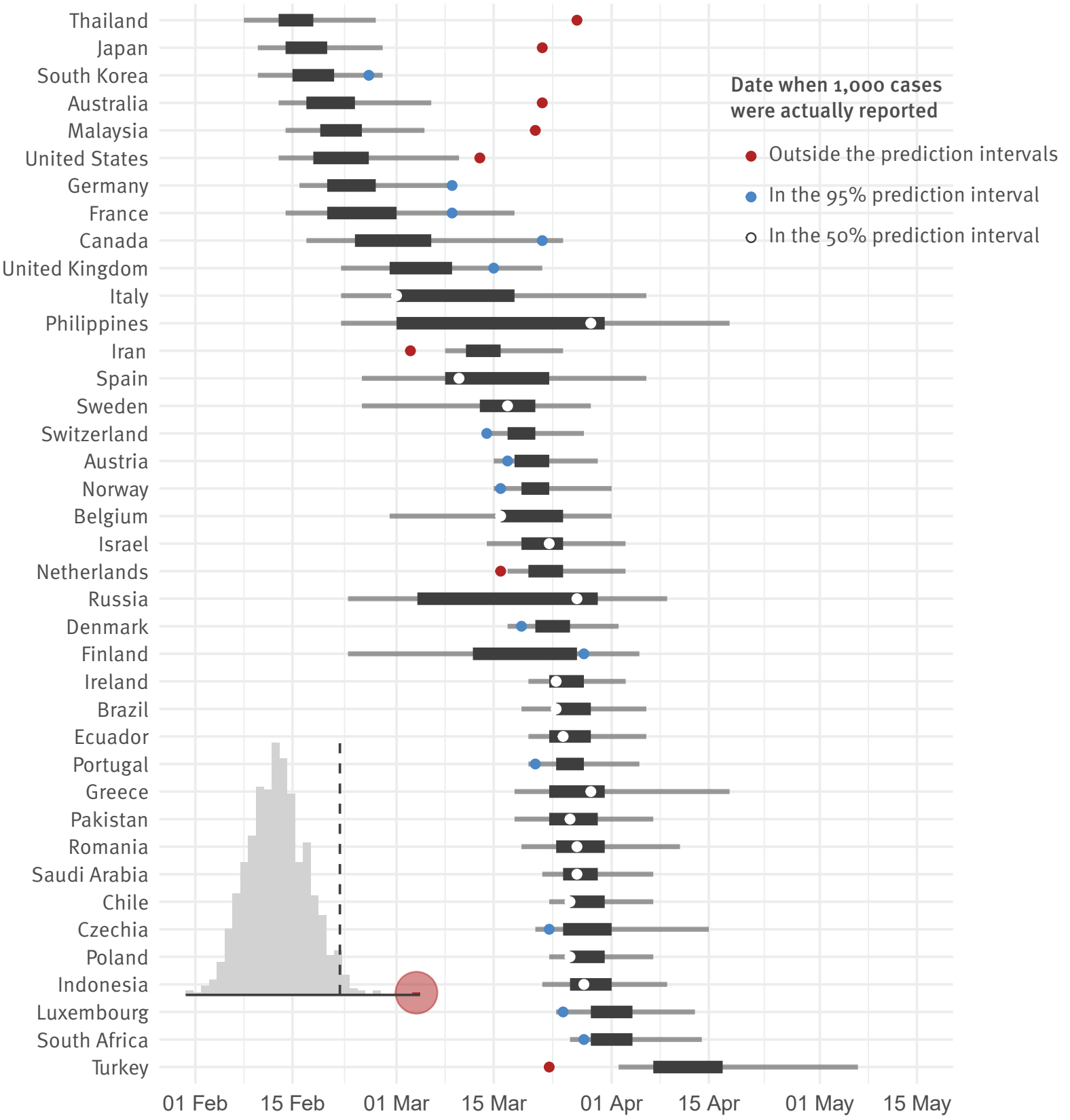

For each country, the predicted date of reaching 1,000 reported cases is within a black horizontal box, representing the $50 \%$ quantiles for the date (i.e. $50 \%$ forecast interval). The grey whiskers surrounding the boxes are $95 \%$ forecast intervals. The dot indicates the actual date when 1,000 reported cases were reached, with white, blue or red colours respectively signalling whether this date falls within the $50 \%$ forecast interval, outside the $50 \%$ forecast interval but still within the $95 \%$ interval, or outside the $95 \%$ interval.

For actual reporting dates, $17 / 39$ fell within the $50 \%$ prediction intervals, and $31 / 39$ within the $95 \%$.

Inset distribution indicates randomisation results: actual forecast (red) vs randomly assigned forecast (grey), with 0.975 quantile indicated by the line. 
language, using the bpmodels package [13], and the data2019nCoV package for the SITREP data [14]. All analysis code is available at https://github.com/ SACEMA/COVID1ok.

\section{Projected timing of 1,000 and 10,000 COVID-19 case reporting in considered African countries/territories}

We projected that all of the 45 African countries reporting cases prior to 23 March 2020 were likely to pass 1,000 reported cases by the end of April 2020 and 10,000 within another few weeks (Figure 1 and Table). Of particular concern is that passing these thresholds is largely synchronised continent-wide and real disease burden will certainly exceed reported cases. Assuming $R=3$ instead, reporting of 1,000 cases occurs roughly 1 week earlier, and 10,000 cases 2 weeks earlier. However, early trends in cases for the $R=3$ scenario rapidly exceeded observed reporting, indicating epidemiological differences; whether those distinctions are in transmission or surveillance and response remains to be determined.

Since our projections assume failed containment of initial cases and no interventions reducing early transmission, they are pessimistic relative to any benefits of local (e.g. those summarised by the stringency index (SI) in the Table) or global action. The international control efforts and travel restrictions to date likely slowed seeding of the epidemic, and other local efforts may have slowed spread once the epidemic was established. However, containment measures, e.g. travel restrictions, increased testing, contact tracing, isolation of cases and quarantine of contacts, are likely to slow, but not halt, real epidemic growth [15]. Indeed, increased testing may accelerate the time to reporting these numbers, as improved ascertainment increases the identified fraction of real cases. However, the model also optimistically assumes surveillance capacity is not overwhelmed or stymied, which would slow reaching 1,000 reported cases while the real disease burden grows uncontrolled. This model also assumes a homogeneous population, neglecting urban vs rural differences as well as connectivity between regions, distinctions, which would tend towards many small outbreaks, rather than the single one we model. Because we ignore these effects, the model is only appropriate for short-range forecasts.

\section{Validation of the model}

As model validation, we applied this same forecasting approach to the 39 countries worldwide that had exceeded 1,000 reported cases by 7 April (SITREP 78) [16]; we did not consider those with more than 10,000 cases, as they all underwent substantial control measures modifying epidemic growth. We found that $17 / 39$ of actual reporting dates fell within the $50 \%$ prediction intervals, and $31 / 39$ within the $95 \%$ interval (Figure 2), indicating the forecast prediction interval is too certain, as expected for a rapid but low detail model. We further showed that forecast performance is not a random outcome by performing a randomisation test: we shuffle the assignment of forecast days-to-1,000-cases to different countries, and score 1,000 shuffled predictions; the real forecast score is significantly different from random at the $p<0.001$ level (Figure 2 inset).

Specific to Africa as of SITREP 93 (22 April 2020), Egypt, Morocco, and South Africa actually reached 1,000 reported cases at a date falling within their $50 \%$ forecast interval, and Algeria within its 95\% interval; Cameroon and Ghana reported 1,000 cases later than their $95 \%$ interval. For 18 other countries the upper time limit of the $50 \%$ forecast interval had already been reached on 22 April, with 11 still in their 95\% interval; one of those had>90o cases (Côte d'Ivoire). Of the seven now past their 95\% interval (Burkina Faso, DR Congo, Nigeria, Rwanda, Senegal, Togo, Tunisia), one has $>900$ cases (Tunisia) and the others generally had early interventions (SI column in the Table).

\section{Conclusions}

Using reporting to date, and assuming similar epidemiological trends to those seen globally, we projected that all of the 45 African countries/territories reporting early cases were likely to report 1,000 cases by the end of April 2020, and 10,000 within another few weeks; with reported cases lagging and under-representing actual burden. Even considering reporting delays, timing is largely synchronised continent-wide. Our projections assumed no substantive changes between the initially reported cases and the forecast points; while some countries have taken drastic actions, invalidating those assumptions, others have not or have acted slowly (SI column in the Table). As seen outside Africa, because onset of severe symptoms can be delayed weeks from infection and last several weeks, interventions have limited immediate impact on new hospitalisations or healthcare facility demand, meaning that most of the countries in our projection would be well past 1,000 real cases by the time the effects of interventions started in late March would be observed.

These results call for further preparations across Africa to ready healthcare systems and citizens for the incoming wave of infections leading to COVID-19; many countries are already making these changes, but more may be required. Augmented staffing, personal protective equipment stores and training, general isolation beds and equipped critical care units are all urgently needed. Citizen awareness will also be critical, and officials should continue to promote preventive measures such as physical distancing and regular hand washing.

SACEMA Modelling and Analysis Response Team (SMART)

Roxanne Beauclair, Elisha B Are, Olatunji O Adetokunboh, Jeremy Bingham, C Marijn Hazelbag, Ivy Kombe, and Joseph B Sempa. 
Centre for Mathematical Modelling of Infectious Disease COVID-19 working group

Emily S Nightingale, Sebastian Funk, Rosalind M Eggo, Joel Hellewell, Adam J Kucharski, Quentin J Leclerc, Nicholas G Davies, Jon C Emery, Stefan Flasche, Nikos I Bosse, Sam Abbott, Megan Auzenbergs, Amy Gimma, Simon R Procter, Rein MGJ Houben, Timothy W Russell, Akira Endo, Charlie Diamond, James D Munday, Gwen Knight, Fiona Yueqian Sun, Yang Liu, Arminder K Deol, Thibaut Jombart, Billy J Quilty, Samuel Clifford, Petra Klepac, Kevin van Zandvoort, Kiesha Prem, Alicia Rosello, Graham Medley, Mark Jit, Christopher I Jarvis, Hamish Gibbs, and W John Edmunds.

\section{Acknowledgements}

CABP gratefully acknowledges funding of the NTD Modelling Consortium by the Bill and Melinda Gates Foundation $\left(\mathrm{OPP}_{1184344)}\right.$ and the Department for International Development / Wellcome Epidemic Preparedness Coronavirus research programme (ref. 221303/Z/20/Z). KMO gratefully acknowledges funding of the Effectiveness of Supplementary Immunization Activities by the Bill and Melinda Gates Foundation (OPP1191821).

CVS, SMART, and JRCP are supported by the South African Centre for Epidemiological Modelling and Analysis (SACEMA), a Department of Science and Innovation - National Research Foundation Centre of Excellence hosted at Stellenbosch University.

\section{Conflict of interest}

None declared.

\section{Authors' contributions}

CABP and JRCP initially developed the analysis and implemented the study. CVS, AMF, and KMO contributed to drafting the text and figures. All authors contributed to processing, cleaning and interpretation of data, interpreted findings, revision of the manuscript, and approved the work for publication.

\section{References}

1. World Health Organization (WHO). Statement on the second meeting of the International Health Regulations (2005) Emergency Committee regarding the outbreak of novel coronavirus (2019-nCoV). Geneva: WHO; 30 Jan 2020. [Accessed 3 Apr 2020]. Available from: https://www.who. int/news-room/detail/30-01-2020-statement-on-the-secondmeeting-of-the-international-health-regulations-(2005)emergency-committee-regarding-the-outbreak-of-novelcoronavirus-(2019-ncov)

2. World Health Organization (WHO). WHO Director-General's opening remarks at the media briefing on COVID-19 - 11 March 2020. Geneva: WHO; 11 March 2020. [Accessed 3 Apr 2020]. Available from: https://www.who.int/dg/speeches/detail/whodirector-general-s-opening-remarks-at-the-media-briefing-oncovid-19---11-march-2020

3. World Health Organization (WHO). Coronavirus disease 2019 (COVID-2019) Situation report - 93. Geneva: WHO; [Accessed 3 Apr 2020]. Available from: https://www.who.int/docs/defaultsource/coronaviruse/situation-reports/20200422-sitrep-93covid-19.pdf?sfvrsn=35cf8od7_4

4. World Health Organization (WHO). Coronavirus disease 2019 (COVID-2019) Situation report - 63. Geneva: WHO; [Accessed 3 Apr 2020]. Available from: https://www.who.int/docs/defaultsource/coronaviruse/situation-reports/20200323-sitrep-63covid-19.pdf

5. Guan WJ, Ni ZY, Hu Y, Liang WH, Ou CQ, He JX, et al. China Medical Treatment Expert Group for Covid-19. Clinical
Characteristics of Coronavirus Disease 2019 in China. N Engl J Med. 2020;382(18):1708-20. https://doi.org/10.1056/ NEJMoa2002032 PMID: 32109013

6. Wu Z, McGoogan JM. Characteristics of and Important Lessons From the Coronavirus Disease 2019 (COVID-19) Outbreak in China: Summary of a Report of 72314 Cases From the Chinese Center for Disease Control and Prevention. JAMA. 2020;323(13):1239. https://doi.org/10.1001/jama.2020.2648 PMID: 32091533

7. Mizumoto K, Kagaya K, Zarebski A, Chowell G. Estimating the asymptomatic proportion of coronavirus disease 2019 (COVID-19) cases on board the Diamond Princess cruise ship, Yokohama, Japan, 2020. Euro Surveill. 2020;25(10). https:// doi.org/10.2807/1560-7917.ES.2020.25.10.2000180 PMID: 32183930

8. Prasad N, Murdoch DR, Reyburn H, Crump JA. Etiology of Severe Febrile Illness in Low- and Middle-Income Countries: A Systematic Review. PLoS One. 2015;10(6):e0127962. https:// doi.org/10.1371/journal.pone.0127962 PMID: 26126200

9. Masanza MM, Nqobile N, Mukanga D, Gitta SN. Laboratory capacity building for the International Health Regulations (IHR[2005]) in resource-poor countries: the experience of the African Field Epidemiology Network (AFENET). BMC Public Health. 2010;10(Suppl 1):S8. https://doi.org/10.1186/14712458-10-S1-S8 PMID: 21143830

10. Abbott S, Hellewell J, Munday J, Funk SCMMID nCoV working group. The transmissibility of novel Coronavirus in the early stages of the 2019-20 outbreak in Wuhan: Exploring initial point-source exposure sizes and durations using scenario analysis. Wellcome Open Res. 2020;5:17. https://doi. org/10.12688/wellcomeopenres.15718.1 PMID: 32322691

11. Bi Q, Wu Y, Mei S, Ye C, Zou X, Zhang Z, et al. Epidemiology and transmission of COVID-19 in 391 cases and 1286 of their close contacts in Shenzhen, China: a retrospective cohort study. Lancet Infect Dis. 2020;S1473-3099(20)30287-5. PMID: 32353347

12. Davies NG, Kucharski AJ, Eggo RM, Gimma A, Edmunds WJ, CMMID COVID-19 Working Group, et al. The effect of nonpharmaceutical interventions on COVID-19 cases, deaths and demand for hospital services in the UK: a modelling study. medRxiv. 2020.04.01.20049908; (Preprint). https://doi.org/10. 1101/2020.04.01.20049908.

13. Funk S. bpmodels: Methods for analysing the sizes and lengths of chains from branching process models. 2020. Available from: https://github.com/sbfnk/bpmodels

14. Brown E. data2019nCov: Data on the 2019 Novel Coronavirus Outbreak (R Package). 2020. Available from: https://github. com/eebrown/data2019nCoV/

15. Hellewell J, Abbott S, Gimma A, Bosse NI, Jarvis $\mathrm{Cl}$, Russell TW, et al. Centre for the Mathematical Modelling of Infectious Diseases COVID-19 Working Group. Feasibility of controlling COVID-19 outbreaks by isolation of cases and contacts. Lancet Glob Health. 2020;8(4):e488-96. https://doi.org/10.1016/ S2214-109X(20)30074-7 PMID: 32119825

16. World Health Organization (WHO). Coronavirus disease 2019 (COVID-2019) Situation report - 78. Geneva: WHO; [Accessed 3 Apr 2020]. Available from: https://www.who.int/docs/defaultsource/coronaviruse/situation-reports/20200407-sitrep-78covid-19.pdf

17. ACAPS. COVID-19 Government Measures. 22 Apr 2020. [Accessed 22 Apr 2020]. Available from: https://data.humdata. org/dataset/acaps-covid19-government-measures-dataset

18. Hale T, Webster S, Petherick A, Phillips T, Kira B. Oxford COVID-19 Government Response Tracker. Blavatnik School of Government; 2020 .

\section{License, supplementary material and copyright}

This is an open-access article distributed under the terms of the Creative Commons Attribution (CC BY 4.0) Licence. You may share and adapt the material, but must give appropriate credit to the source, provide a link to the licence and indicate if changes were made.

Any supplementary material referenced in the article can be found in the online version.

This article is copyright of the authors or their affiliated institutions, 2020. 